\title{
Combining Meteosat-10 satellite image data with GPS tropospheric path delays to estimate regional integrated water vapor (IWV) distribution
}

\author{
Anton Leontiev ${ }^{1}$ and Yuval Reuveni ${ }^{2,3,4}$ \\ ${ }^{1}$ Department of Electrical Engineering, Ariel University, Ariel, Israel \\ ${ }^{2}$ Department of Mechanical Engineering \& Mechatronics, Ariel University, Ariel, Israel \\ ${ }^{3}$ Eastern R\&D Center, Ariel, Israel \\ ${ }^{4}$ School of Sustainability, Interdisciplinary Center (IDC) Herzliya, Herzliya, Israel
}

Correspondence to: Yuval Reuveni (vlf.gps@gmail.com)

Received: 28 June 2016 - Discussion started: 10 August 2016

Revised: 7 January 2017 - Accepted: 20 January 2017 - Published: 14 February 2017

\begin{abstract}
Using GPS satellites signals, we can study different processes and coupling mechanisms that can help us understand the physical conditions in the lower atmosphere, which might lead or act as proxies for severe weather events such as extreme storms and flooding. GPS signals received by ground stations are multi-purpose and can also provide estimates of tropospheric zenith delays, which can be converted into accurate integrated water vapor (IWV) observations using collocated pressure and temperature measurements on the ground. Here, we present for the first time the use of Israel's dense regional GPS network for extracting tropospheric zenith path delays combined with near-realtime Meteosat-10 water vapor (WV) and surface temperature pixel intensity values ( 7.3 and $10.8 \mu \mathrm{m}$ channels, respectively) in order to assess whether it is possible to obtain absolute IWV $\left(\mathrm{kg} \mathrm{m}^{-2}\right)$ distribution. The results show good agreement between the absolute values obtained from our triangulation strategy based solely on GPS zenith total delays (ZTD) and Meteosat-10 surface temperature data compared with available radiosonde IWV absolute values. The presented strategy can provide high temporal and special IWV resolution, which is needed as part of the accurate and comprehensive observation data integrated in modern data assimilation systems and is required for increasing the accuracy of regional numerical weather prediction systems forecast.
\end{abstract}

\section{Introduction}

Water vapor (WV) is a greenhouse gas, which can lead to global warming. It repetitively cycles through evaporation and condensation phases, transporting heat energy around the Earth and between the surface and the atmosphere (Solomon et al., 2010). WV in the atmosphere allows short wavelength radiation from the sun to propagate through the atmosphere, but it traps the long wavelength radiation emitted by the Earth's surface (van Vleck, 1947). This trapped radiation causes temperatures to increase. As the temperatures increase, the air can sustain a larger amount of WV, thus magnifying the greenhouse effect (Duan et al., 1996). Since WV is the most variable component of the troposphere, investigation of its distribution and motion is of great importance in meteorology and climatology (Soden et al., 2004). Although it plays a key role in determining climate sensitivity, our current ability to constantly monitor changes in $\mathrm{WV}$ at high spatial resolution is insufficient (Kley et al., 2000; Wang et al., 2016). Above the tropical oceans where long-term microwave satellite measurements are obtainable, atmospheric reanalysis products indicate $\mathrm{WV}$ patterns that are different from the satellite data from 1988 to 2012, and most climate models indicate significantly larger WV trends than the satellite observations (Flato et al., 2013), probably due to different parameterizations of internal climate variability in models and observation. Above land, it is even more challenging, where large errors in radiosonde humidity data (which are currently main source of observations) degrade many of 


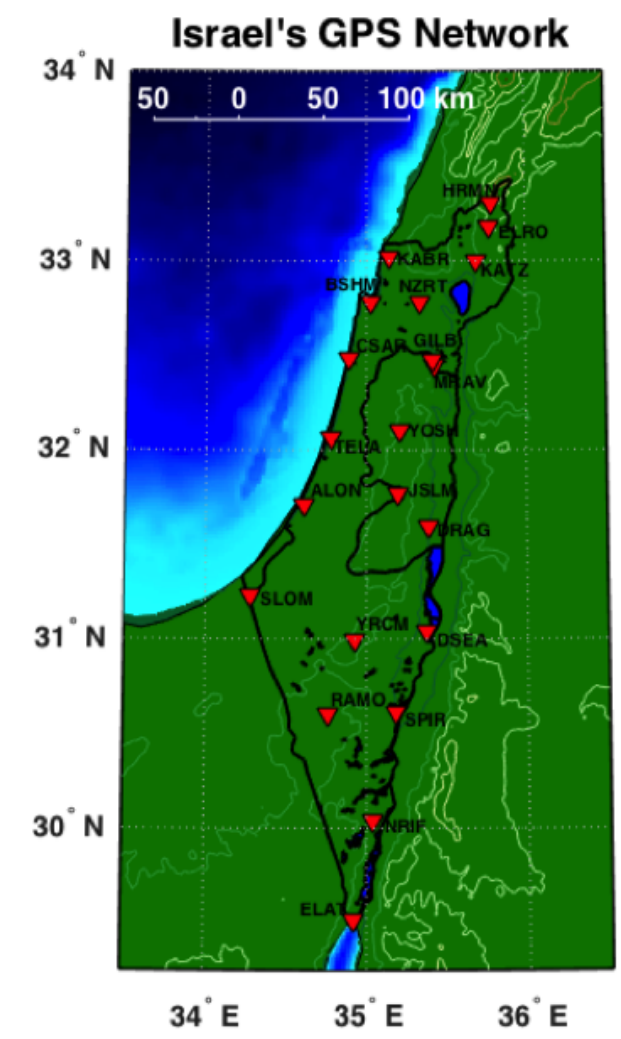

Figure 1. Israel's GPS network. The network is maintained by the Survey of Israel (MAPI) and consist of 24 permanent geodetic GPS receivers.

the reanalysis and observational products (Dai et al., 2011, 2013).

There are several approaches for estimating the amount of WV in the troposphere. The most common ones utilize radiosondes (Kley et al., 2000; Soden et al., 2004; Miloshevich et al., 2006), different techniques of GPS meteorology (Bevis et al., 1992, 1994; Duan et al., 1996; Ware and Alber, 1997; Hagemann and Bengtsson, 2003; Vedel et al., 2004; Heise et al., 2009; Guerova et al., 2013; Hordyniec et al., 2015) or measurements from remote sensing satellites (Velden et al., 1997; Cresswell et al., 1999; Jiang et al., 2012). Radiosondes offer an essential component of the global observing system due to their extended lifetime and broad geographic coverage (Kley et al., 2000). Radiosondes have long been the main observing platform for monitoring tropospheric WV and are still widely used to provide WV profiles both for field campaigns and as part of national observing networks (Soden et al., 2004). Radiosondes observations have the advantage of delivering high vertical resolution acquisition under clear and cloudy conditions as well as having long historical records (Soden and Lanzante, 1997). However, substantial spatial and temporal discontinuities, frequently related to differences in radiosondes instrumentation, have also been well documented (Elliott and Gaffen, 1991; Soden and Lanzante,

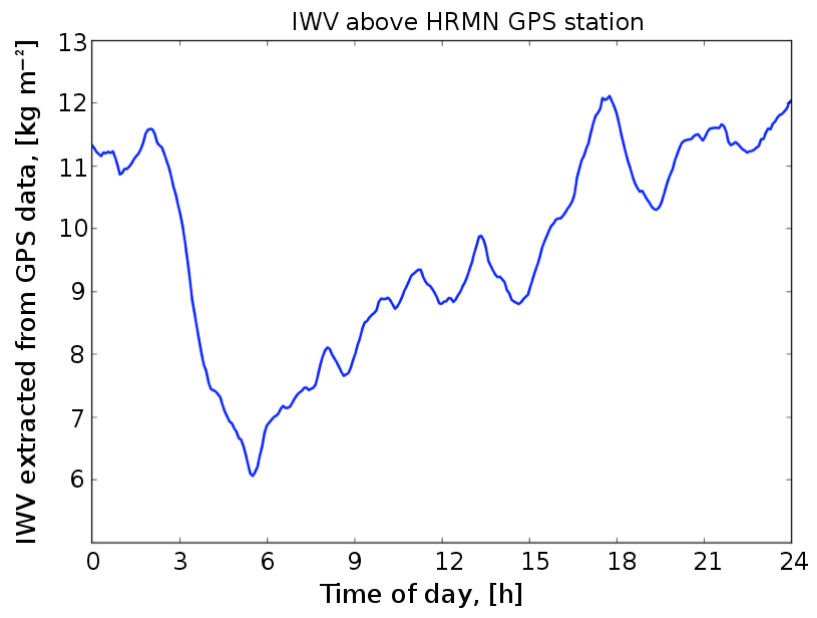

Figure 2. Distribution of IWV above GPS station HRMN during 25 May 2015.

1997; Free and Durre, 2002). Furthermore, there are still national observing networks (i.e., the Israel Meteorological Service, or IMS) which conduct upper-air measurements to characterize the temporal behavior of the lower atmosphere from a single permanent sounding site (Dayan and Rodnizki, 1999). This makes it almost impossible to precisely detect the horizontal boundaries between moist and dry air, especially when most radiosondes are launched at $12 \mathrm{~h}$ intervals that deliver limited temporal resolution (Moore et al., 2015).

When electromagnetic signals travel through the troposphere, they are delayed and therefore slowed down. The amount of delay depends mainly on the pressure, temperature and WV content, which vary significantly both in space and time (Reuveni et al., 2015). Geophysicists and geodesists have developed methods for estimating the degree to which signals propagating from GPS satellites to ground-based GPS receivers are delayed by atmospheric WV (Wdowinski and Eriksson, 2009). This delay is parameterized in terms of a time-varying zenith wet delay (ZWD) that is recovered by stochastic filtering of the GPS data (Bevis et al., 1992, 1994; Duan et al., 1996). Currently, GNSS meteorology can provide continuous remote monitoring with high temporal and spatial resolution of the $\mathrm{WV}$ in the troposphere as long as the pressure and temperature are measured at the observation sites. However, systematic errors under $0.5 \mathrm{~mm}$ are still introduced into WV estimations and, when using pressure interpolation procedure, biases $>0.5$ and $1 \mathrm{hPa}$ standard deviation are introduced into the system (Hordyniec et al., 2015). Furthermore, the GPS integrated water vapor (IWV) estimations are generally validated by comparison either with radiosonde data (Moore et al., 2015), ECMWF IWV estimates (Heise et al., 2009) or water vapor radiometer (WVR) data (Shangguan et al., 2015), thus allowing us to obtain reasonable initial conditions data for creating new numerical models of zenith total delay (ZTD) and IWV for meteorological applications 


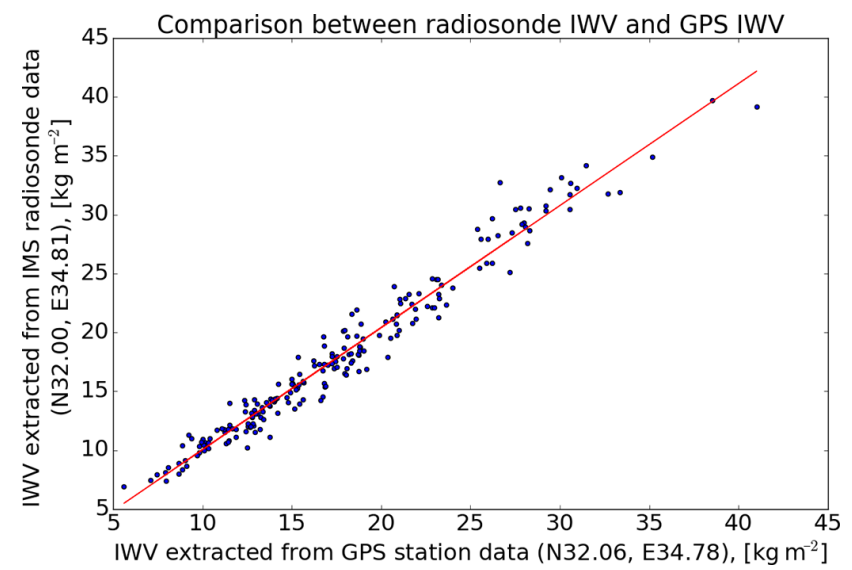

Figure 3. Comparison between IWV $\left(\mathrm{kg} \mathrm{m}^{-2}\right)$ extracted from IMS radiosonde and GPS data (based on the ZTD and ZHD values from the VMF1 grid every $6 \mathrm{~h}$ ) for approximately 240 days during the year 2015 . The correlation shows good agreement $\left(R^{2}=0.97\right)$ between the two data sets. GPS IWV values were estimated from ZWD and IMS surface temperature measurements. Mean and RMS values for the differences between the two data sets are 0.32 and $1.34 \mathrm{~kg} \mathrm{~m}^{-2}$, respectively.

(Sadeghi and Mashhadi-Hossainali, 2014; Dembelov et al., 2015; Calori et al., 2016). In addition, reprocessed GNSS ZTD and IWV data can also be used for assessing the accuracy of near-real-time ZTD network products (such as the European Meteorological Services EIG EUMETNET-GNSS WV program, E-GVAP) assimilated in operational numerical weather prediction systems as well as validation of IWV data from radiosonde observations (Bock et al., 2015).

Satellite observations of reflected infrared (IR) radiation in the WV absorption bands can also provide a unique source of information on tropospheric WV (Soden and Lanzante, 1997). Within the thermal IR domain, the European geostationary Meteosat satellites are capable of almost continuously monitoring (every $15 \mathrm{~min}$ with Meteosat-10), while observing the Earth in the atmospheric window $(8.7-13.4 \mu \mathrm{m})$ and WV absorption frequency bands $(6.2$ and $7.3 \mu \mathrm{m})$. The Meteosat WV channels are mainly used in operational meteorology to detect the development of upper-tropospheric WV structures and carry signatures of the atmospheric conditions (Hanssen et al., 2001). Because of the strong absorption by WV at these wavelengths, the observed brightness temperatures usually originate from tropospheric layers above $3 \mathrm{~km}$ (de Haan et al., 2004). Therefore, quantitative estimation is limited to upper-tropospheric WV (Bréon et al., 2000). The spatial resolution at the satellite point corresponds to $5 \times 5 \mathrm{~km}^{2}$ for the IR and WV channels. The Meteosat IR and WV channel observations are taken in the engineering quantity "count" mode and have to be converted into equivalent physical "radiance" units (Schmetz et al., 1997). The calibration is accomplished by linking the observed clear sky WV pixel values to a calculated radiance at the top of the atmosphere as determined by radiative transfer calculations using temperature and humidity profiles from radiosondes. This could lead to bias errors of up to $5 \%$, which corresponds to approximately $1 \mathrm{~K}$ in brightness temperature. Furthermore, the temperature values derived from Meteosat are an indication of reflected long-wave radiation rather than the true value of ambient air temperature, and they therefore also need to be adjusted (Cresswell et al., 1999). Nevertheless, the main advantage of using satellite data such as from Meteosat is the ability to obtain WV and surface temperature distribution on regional or global scale (Roca et al., 1997). However, because the abundance of WV is highest near the Earth's surface, where relatively high temperature and pressure permit the air to contain more $\mathrm{WV}$, it is not possible to make one unique parameterization of WV channel brightness temperatures into IWV (Hanssen et al., 2001). In addition, retrieval of total WV from observations in the thermal IR split-window channels at 10.8 and $12.0 \mu \mathrm{m}$ of the Meteosat Second Generation-Spinning Enhanced Visible and Infrared Imager (MSG-SEVIRI) over varying surface temperatures requires a nonlinear approach in order to make it applicable to the full range of global atmospheric conditions (Schroedter-Homscheidt et al., 2008). Recently, it has been shown that convective rainfall rate (CRR) can be derived using the 10.8 and $6.2 \mu \mathrm{m}$ MSG-SEVIRI from the algorithm developed within the Satellite Application Facility with Support to Nowcasting and Very Short-Range Forecasting (NWC $\mathrm{SAF})$, but it still needs to be calibrated using matrices generated from both SEVIRI and radar data (Ivančan-Picek et al., 2014).

Here, we investigate whether it is possible to obtain absolute IWV $\left(\mathrm{kg} \mathrm{m}^{-2}\right)$ distribution using GPS ZTD estimations combined with near-real-time Meteosat-10 WV and surface temperature pixel intensity values. We argue that using GPS meteorology coupled with Meteosat surface temperature and $\mathrm{WV}$ interpolated data can produce adequate results for WV estimation for Israel for periods when the descending air in the subsidence inversion is rather dry and the absorption (and emission) of radiation is low (i.e., the air is relatively transparent and allow radiation from lower (warmer) layers to contribute to the signal, which results in high apparent brightness temperatures). We present our results for estimating WV content around Israel and the Middle East area using different techniques, comparing their validity and choosing the best strategy for estimating WV distribution.

\section{Technical approach and methodology}

In this paper we calibrate Meteosat WV pixel values for Israel using IWV obtained from all available GPS stations around Israel (Fig. 1). First, we estimate IWV values above each GPS station using the Jet Propulsion Laboratory's (JPL) GIPSY-OASIS precise point positioning (PPP) software and tropospheric products (Zumberge et al., 1997; Bertiger et al., 
(a) Comparison between radiosonde IWV and GPS IWV

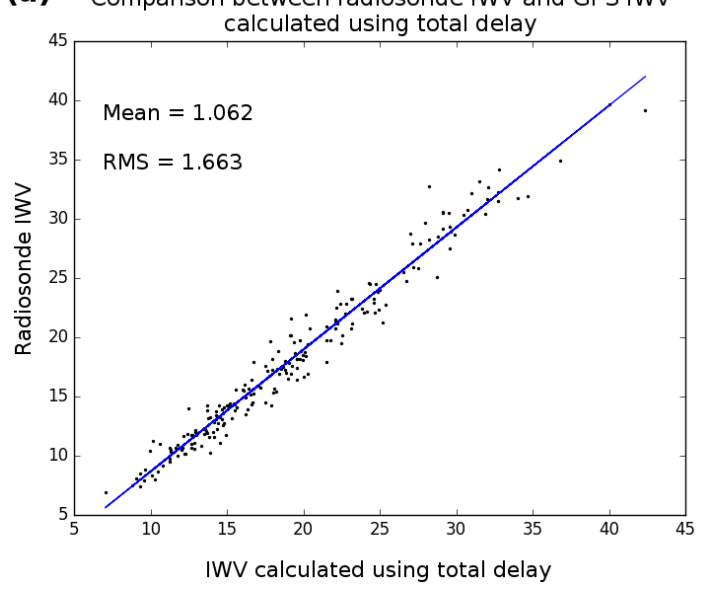

(b) Comparison between radiosonde IWV and GPS IWV

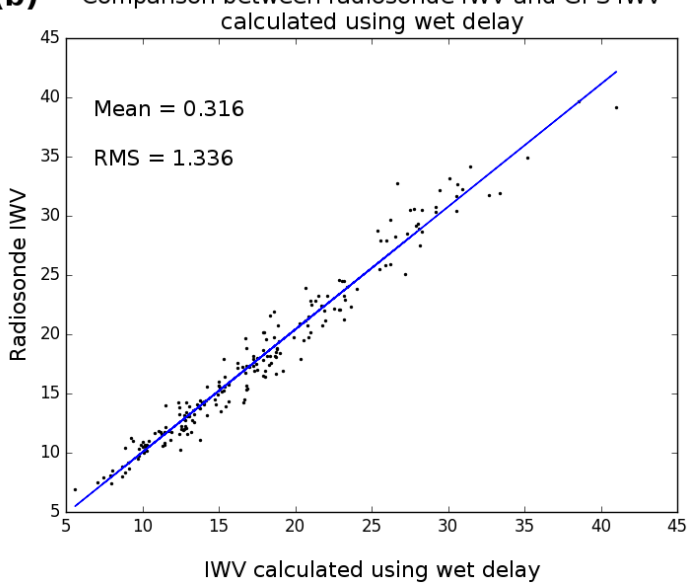

Figure 4. (a) Comparison between estimated IWV based on the ZTD and ZHD values from IMS pressure and temperature measurements and radiosonde measurements for approximately 240 days during the year 2015. Mean and RMS values for the differences between the two data sets are 1.062 and $1.663 \mathrm{~kg} \mathrm{~m}^{-2}$, respectively. (b) Comparison between estimated IWV based on the ZTD and ZHD values from the VMF1 grid every six and radiosonde measurements. Mean and RMS values for the differences between the two data sets are 0.32 and $1.34 \mathrm{~kg} \mathrm{~m}^{-2}$, respectively.

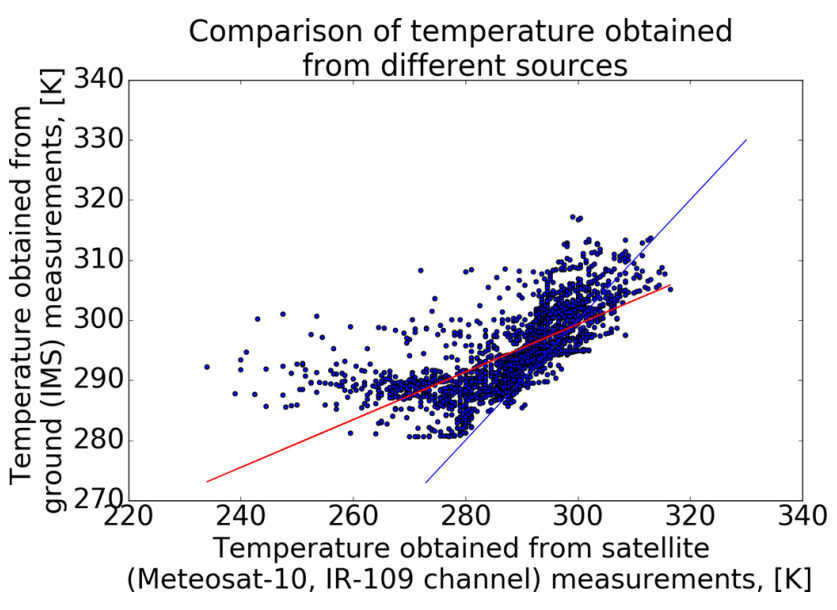

Figure 5. Comparison between Meteosat-10 and IMS temperature measurements. The red line represents a linear fit $\left(R^{2}=0.69\right)$ for the temperatures values obtained from Meteosat-10 and IMS. The blue line represents the area where both data sets are completely equal. Mean and RMS values are 6.62 and $10.75 \mathrm{~K}$, respectively.

2010; Reuveni et al., 2012, 2014, 2015). The IWV estimation is based on tropospheric ZWD and gradient, tropospheric dry delay and surface temperature values. Second, WV pixel values obtained from Meteosat-10 images are obtained for the GPS stations' location. Finally, a mathematical dependency is found between the two data sets, which allows transformation of the entire Meteosat-10 WV pixel values to absolute WV values.

\subsection{IWV estimation from GPS}

The GPS data retrieved from the SOPAC archive (http:// sopac.ucsd.edu/) are from stations of the Survey of Israel (MAPI) GPS network (Fig. 1). The GPS data were processed separately for each day using the JPL GIPSY-OASIS PPP software and products. A $7^{\circ}$ minimum elevation cutoff for the satellite observations was applied along with the Vienna Mapping Function 1 (VMF1; Boehm et al., 2006). Zenith hydrostatic delay (ZHD) values from the VMF1 grid were used every $6 \mathrm{~h}$. The GIPSY-OASIS software applied in this study considers the tropospheric zenith delay and gradients as stochastic parameters to enable time-varying behavior. Stochastically time-varying parameters are assumed to be constant within each time step, but they may change from one time step to another. After a measurement has been processed (and the parameter estimation had been updated), a time update is executed, adding process noise to the parameter uncertainties in order to simulate unmodeled or mismodeled effects (Reuveni et al., 2012). The tropospheric zenith wet delay and the gradient parameters are allowed to vary within $5.0 e-8 \mathrm{~km} / \sqrt{\mathrm{s}}$ (corresponds to about $3 \mathrm{~mm}$ in an hour) and $5.0 e-9 \mathrm{~km} / \sqrt{\mathrm{s}}$ (corresponds to about $0.3 \mathrm{~mm}$ in an hour), respectively. Once the ZWD value is obtained for a specific time interval (i.e., $5 \mathrm{~min}$ ) the IWV can be easily calculated using the surface temperature (Bevis et al., 1992):

$\mathrm{IWV}=\kappa \mathrm{ZWD}$,

where $1 / \kappa=10^{-6}\left(k_{3} / T_{\mathrm{m}}+k_{2} / R_{v}\right), k_{3}=3.776 \cdot 10^{5} \mathrm{~K}^{2}$ $\mathrm{mbar}^{-1} k_{2}=64.79 \mathrm{mbar}^{-1}, R_{v}$ is the specific gas constant for $\mathrm{WV}$ and $T_{\mathrm{m}}$ is the weighted mean temperature. Furthermore, $T_{\mathrm{m}}$ might be simply approximated with 


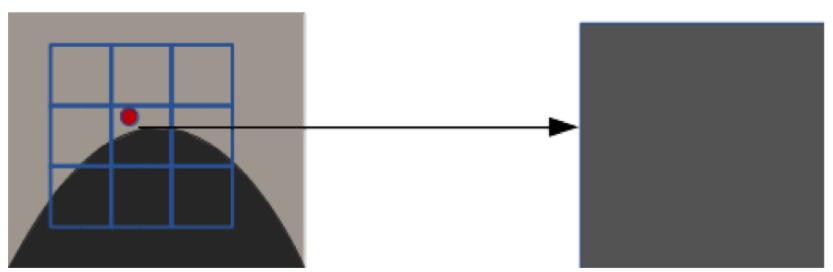

Figure 6. Problematic satellite image pixels which fall near water sources; the actual measured pixel value is averaged between the ground and water temperatures. Dark areas represent water source (low temperatures), while the light areas represent the surrounding ground (high temperatures). The red point represents the location for ground station surface temperature measurements. The actual averaged pixel value is shown on the right.

$T_{\mathrm{m}}=70.2+0.72 T_{\mathrm{s}}$

where $T_{\mathrm{S}}$ represents the surface temperature. For the GPS IWV estimations, we used the nearest $(<10 \mathrm{~km}$ radius $)$ surface temperature values measured by the IMS to each GPS site (http://www.ims.gov.il/IMSEng/All_tahazit/). Figure 2 represents the IWV values for GPS station HRMN $\left(33^{\circ} 18^{\prime} 30^{\prime \prime} \mathrm{N}, 35^{\circ} 47^{\prime} 07^{\prime \prime} \mathrm{E}\right)$ using the procedure described above. In order to validate that the GPS IWV is accurate, we compared against the absolute IWV values estimated from IMS radiosonde data (Fig. 3), which is considered to be the most accurate method for obtaining IWV observations. The comparison between the two data sets shows a high correlation coefficient $\left(R^{2}=0.97\right)$ for all available data during 2015 (approximately 240 days). Mean bias and RMS values between the two data sets are 0.32 and $1.34 \mathrm{~mm}$, respectively. Furthermore, in order to validate that the estimated ZWD delays using ZTD and ZHD values from VMF1 are reasonably accurate (both in terms of bias and error), we also compared the estimated IWV based on the ZTD and ZHD values obtained from IMS pressure and temperature observations (Fig. 4).

The closest GPS station to the radiosonde at Bet Dagan is TELA station at Tel Aviv, situated $9 \mathrm{~km}$ from Bet Dagan. The pressure data were taken from the IMS station at Bet Dagan (because of the absence of the pressure measurements near TELA station) and were adjusted accordantly using the relative height difference between Bet Dagan and GPS station TELA. The temperature data were taken from the IMS station at the exact location of GPS station TELA. Mean and RMS values for the differences between the estimated IWV based on the ZTD and ZHD values obtained from the IMS pressure and temperature measurements and radiosonde data are 1.062 and $1.66 \mathrm{~mm}$, respectively, indicating that the estimated IWV using ZHD values from the VMF1 grid every $6 \mathrm{~h}$ has smaller bias and RMS errors.

While processing the entire Israeli GPS network we discovered that precise temperature measurements for all the GPS station location could not be fully obtained due to the

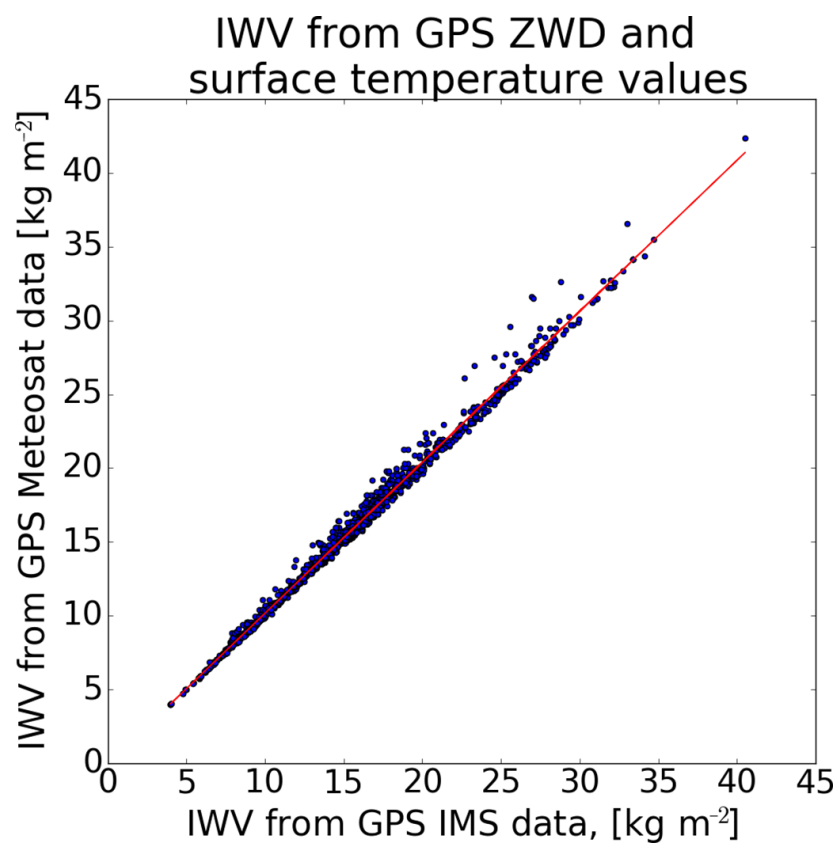

Figure 7. Comparison between IWV obtained using GPS ZWD produced using Meteosat-10 surface temperatures $(12 \mu \mathrm{m}$ IR channel) and GPS ZWD produced using IMS measured temperatures. The correlation between the two is very high $\left(R^{2}=0.99\right)$, indicating that the extracted IWV has a stronger dependency on GPS ZWD rather than the measured surface temperatures. Mean and RMS value are 0.27 and $0.49 \mathrm{~kg} \mathrm{~m}^{-2}$, respectively.

fact that several IMS stations are outside our predefined GPS surrounding area ( $<10 \mathrm{~km}$ radius). Within a network of 24 permanent GPS stations, which are designated to deliver full spatial coverage for a $20000 \mathrm{~km}^{2}$ area, the surface temperature data for each GPS location are critical for establishing the mathematical dependency between GPS IWV and Meteosat-10 WV data. One way to solve this problem is to use the $10.8 \mu \mathrm{m}$ Meteosat-10 IR channel to estimate the surface temperature at the GPS station locations (Muller, 2010). A comparison between the surface temperature estimation from Meteosat-10 and IMS measurements is shown in Fig. 5. The correlation between the two is moderate $\left(R^{2}=0.69\right)$, and in most cases the bias between the two does not normally exceed $5^{\circ} \mathrm{C}$. However, temperature differences may be higher when satellite image pixel falls near water sources such as the Mediterranean Sea, Dead Sea, Gulf of Aqaba and lake Kinneret, and the measured pixel value is averaged between the ground and water temperatures (Fig. 6). Averaging the surrounding pixels values above a pre-determined threshold can help reducing these temperature differences. For example, we took the exact pixel, which corresponds to the exact station location, and then averaged the square $3 \times 3$ pixels around the station. Each pixel of Meteosat-10 image covers an area ranging from $3 \times 3$ up to $11 \times 11 \mathrm{~km}^{2}$, depending on 


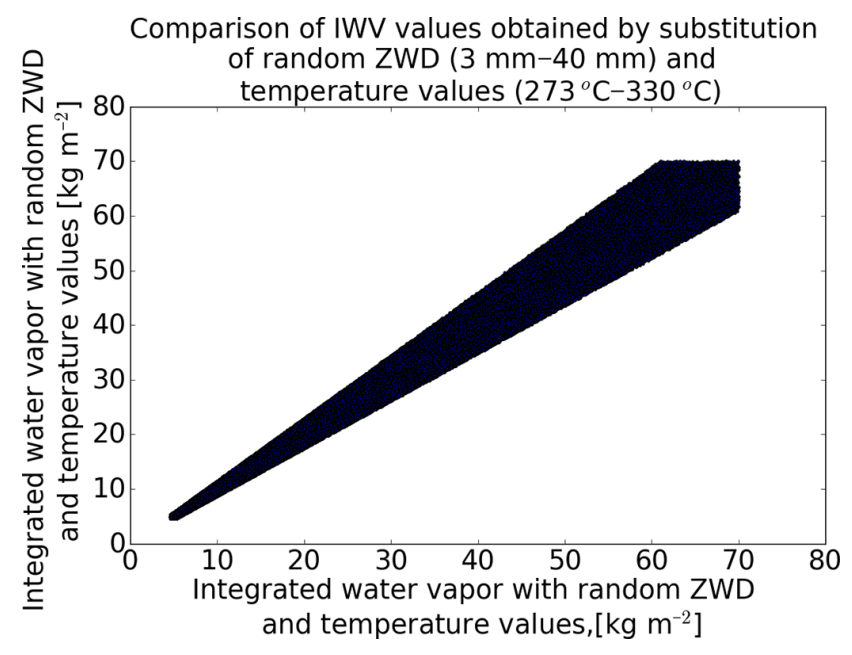

Figure 8. Simulation of IWV dependency on ZWD and temperature. We used 1 million random ZWD values along with two random temperature values (one for the Meteosat and one for the IMS) ranging from 273 to $330 \mathrm{~K}$. The high correlation $\left(R^{2}=0.98\right)$, which is obtained along with the RMS value $2.25 \mathrm{~kg} \mathrm{~m}^{-2}$, suggests that it is possible to calculate IWV precisely enough using the correct ZWD estimation with any temperature data, even when the difference between the absolute and measured temperature value is big.

the longitude and latitude. For Israel, each pixel covers an area of approximately $5 \times 5 \mathrm{~km}^{2}$.

In spite of the moderate correlation $\left(R^{2}=0.69\right)$ between surface temperatures obtained from the $10.8 \mu \mathrm{m}$ Meteosat-10 IR channel and other available measured temperature sources (on-site reading or IMS stations), Meteosat-10 surface temperature values produce approximately similar WV absolute values. Figure 7 represents the comparison between WV estimation using GPS ZWD derived using IMS surface temperatures and GPS ZWD derived using Meteosat-10 surface temperature. The correlation between the two is very high $\left(R^{2}=0.99\right)$ and indicates that using GPS ZWD using Meteosat-10 surface temperatures for estimating IWV can also reach accurate absolute IWV values. These results suggest that the extracted IWV has a stronger dependency on GPS ZWD rather than the measured surface temperature (Bar-Sever et al., 1998). The IWV is a function of the temperature (dependency $\kappa(T)$ ) and ZWD. The coefficient $\kappa$ is a weak function of temperature and the IWV depends on ZWD linearly. Figure 8 represents the results for simulating the IWV dependency on ZWD and temperature. We used random values for ZWD ranging from 3 to $40 \mathrm{~mm}$, and for each value of the ZWD two random temperature values (one for the Meteosat and one for the IMS) ranging from 273 to $330 \mathrm{~K}$ were substituted to the coefficient $k$ in Eq. (1). This simulates the temperatures obtained from the two different sources. Simulation using 1 million points also yields high correlation $\left(R^{2}=0.98\right)$ with RMS value equal to $2.25 \mathrm{~kg} \mathrm{~m}^{-2}$. This result implies that it is possible to calculate IWV precisely

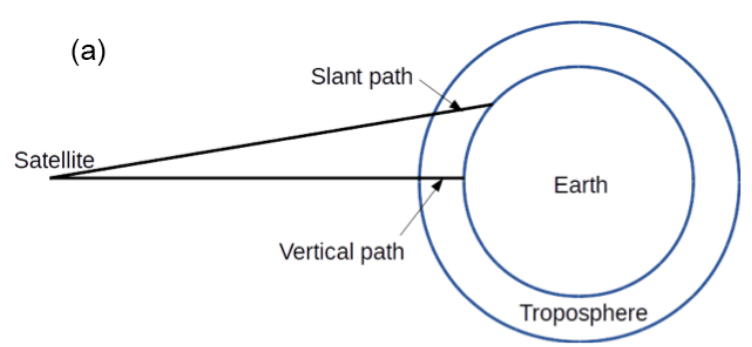

(b)

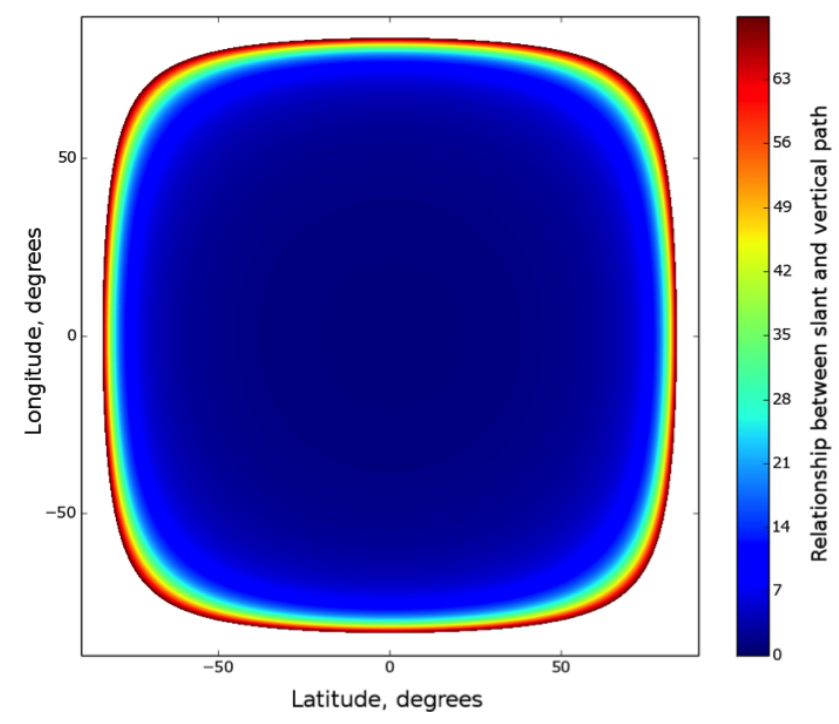

Figure 9. (a) Conceptual geometry of the satellite slant and vertical paths relative to the Earth's surface. (b) Normalization function (Eq. 1) for latitude and longitude dependency.

enough using the correct ZWD estimation with any temperature data, even when the difference between the absolute and measured temperature value is relatively large.

\subsection{WV estimation from Meteosat-10}

For processing the raw Meteosat-10 data we used the Python module Pytroll (http://www.pytroll.org/) to obtain images for all satellite channels. For the temperature estimation we used 8 bit pictures of the $10.8 \mu \mathrm{m}$ IR channel and for the WV estimation we used the $7.3 \mu \mathrm{m} \mathrm{WV}$ channel. Meteosat-10 WV (6.2 and $7.3 \mu \mathrm{m}$ ) images represent the slant path between the satellite and a specified point at the Earth's surface (rather than the vertical WV amount above the point). Therefore, the satellite image pixel values should be normalized at each point to obtain the vertical path (Fig. 9a). Under the assumption that the descending air in the subsidence inversion is rather dry, the absorption of radiation is low and the IWV is distributed uniformly around the Earth (only for the purpose of projecting correctly the slant to vertical absorption), we can obtain a straightforward normalization function $k(\phi, \lambda)$, which is longitude and latitude dependent: 


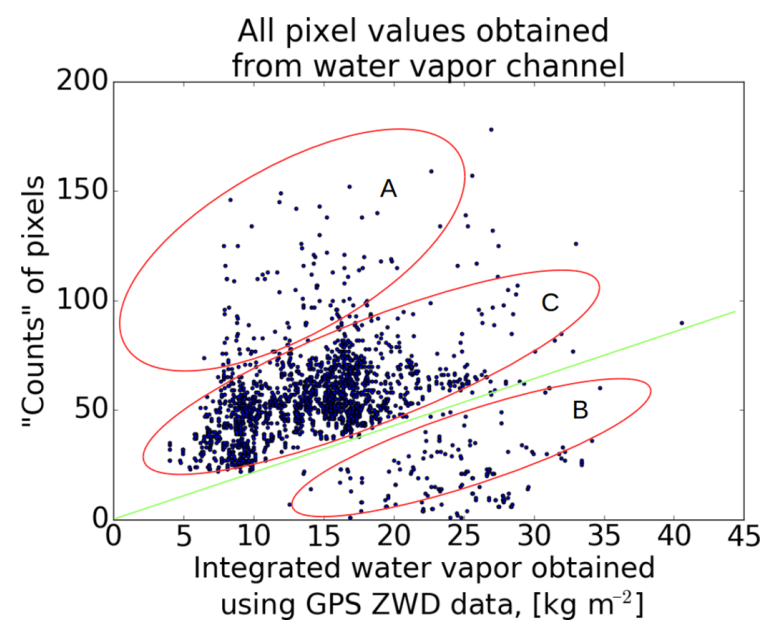

Figure 10. Extracting the dependency between Meteosat-10 normalized pixel values and GPS IWV absolute values (using surface temperatures from IMS stations). The dependency was calculated from 276 Meteosat-10 images and 22 GPS stations. The entire data set can be divided into three main regions, which depend on the station location, weather conditions (mainly clouds) and satellite position. Region A corresponds to the state illustrated in Fig. 11a, and region B corresponds to Fig. 11b. The green line represents the area where both data sets are completely equal.

$k=(L-l) / h$

where

$$
\begin{aligned}
l & =\frac{2(r+H) \cos \beta-\left((2 \times(r+H) \cos \beta)^{2}-4(H-h)(H+h+2 r)\right)^{1 / 2}}{2} \\
L & =\left((r+h)^{2}+r^{2}-2 r H \cos \alpha\right)^{1 / 2}
\end{aligned}
$$

$\alpha=a \cos (\cos \phi \cos \lambda)$

$\beta=\sin \left(\frac{r \sin \alpha}{L}\right)$

where $\phi$ and $\lambda$ are the latitude and longitude, respectively, $H$ is the height of the geostationary orbit $(H=35786 \mathrm{~km})$, $h$ is the height of the troposphere $(h=10 \mathrm{~km})$ and $r$ is the Earth's radius $(r=6371 \mathrm{~km})$. The term in Eq. (3) depends strongly on the ratio between the tropospheric height and the distance from the point at the surface to the satellite. In our estimations, we assume the troposphere height is equal to $10 \mathrm{~km}$. The troposphere extends upwards above the boundary layer and ranges in height from an average of $9 \mathrm{~km}$ at the poles to $17 \mathrm{~km}$ at the Equator. Consequently, for regional areas this height might be calculated more precisely using regional neutral atmosphere models or in situ observations that take into account horizontal inhomogeneities and other local factors (such as winds, air flows and convection). The dependency of the function given in Eq. (3) on latitude and longitude is shown in Fig. 9b. (a)

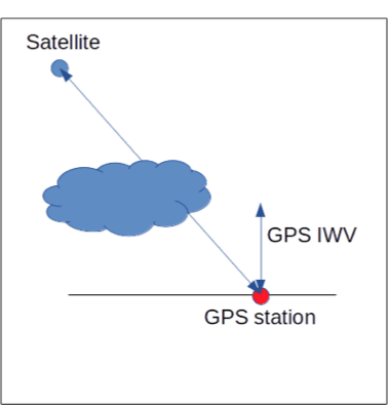

(b)

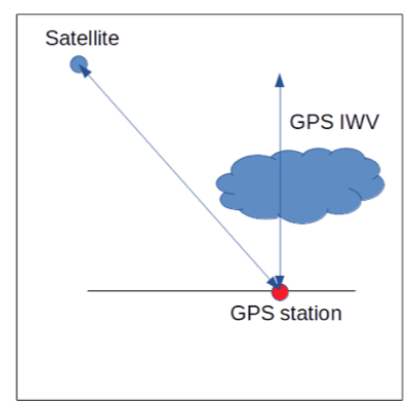

Figure 11. Two options of mutual location of clouds, GPS station and satellite. (a) Estimated GPS IWV values are taken from station at clear sky conditions but with a line of sight (from the satellite to the station) which crosses the clouds. In this case the temperatures obtained from the Meteosat-10 images are more than $5 \mathrm{~K}$ cooler relative to the IMS ground measurements. (b) Estimated GPS IWV values are taken from stations at cloudy conditions but with a line of sight which does not cross the clouds. In this case the estimated Meteosat-10 temperatures are approximately equal to the IMS temperatures but the estimated IWVs are lower than the actual values.

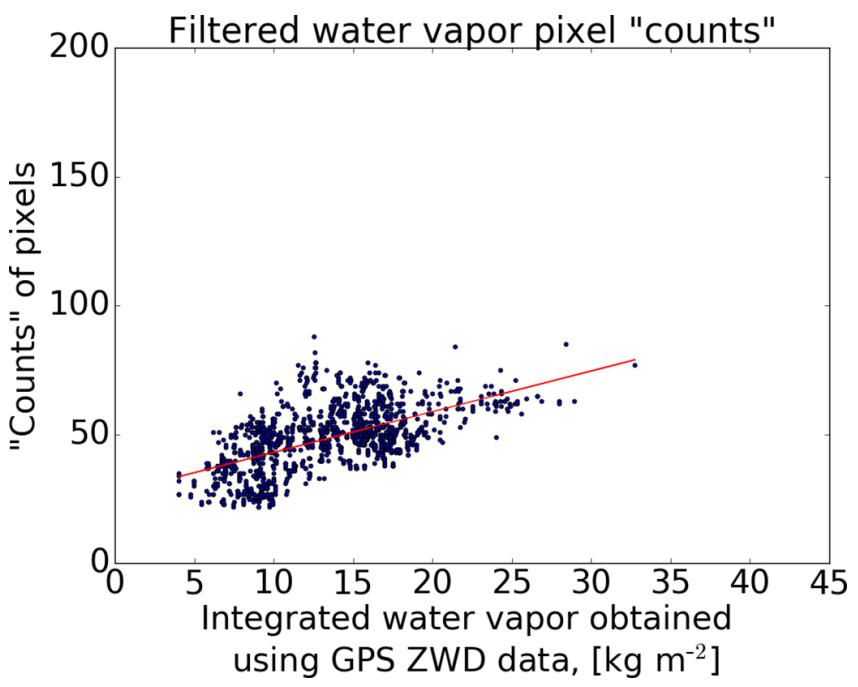

Figure 12. Filtered dependency between Meteosat-10 normalized pixel values and GPS IWV absolute values. The data plotted are the remaining $\mathrm{C}$ region (Fig. 10) measurement points.

Once all Meteosat-10 WV image pixels are normalized, we can then extract the mathematical dependency between the satellite pixel values and absolute IWV values obtained from GPS ZTD and surface temperature values. The dependency between the satellite normalized pixel values and GPS IWV is shown in Fig. 10. The dependency was calculated from 276 Meteosat-10 images and 22 GPS stations. Furthermore, the distribution of entire data set can be divided to three main regions, which depend on the station location, weather conditions (mainly cloudy) and satellite position. Region A consists of estimated GPS IWV values taken from a GPS sta- 
(a)

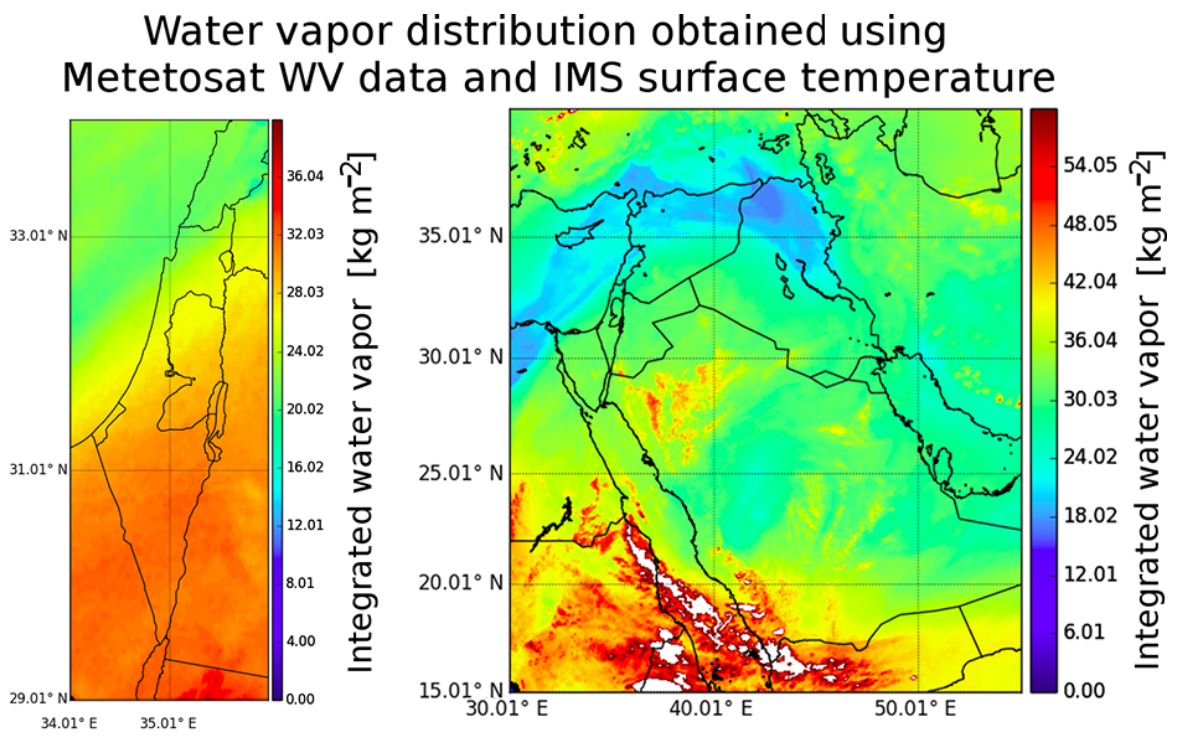

(b) Water vapor distribution obtained using Metetosat WV data and Meteosat surface temperature
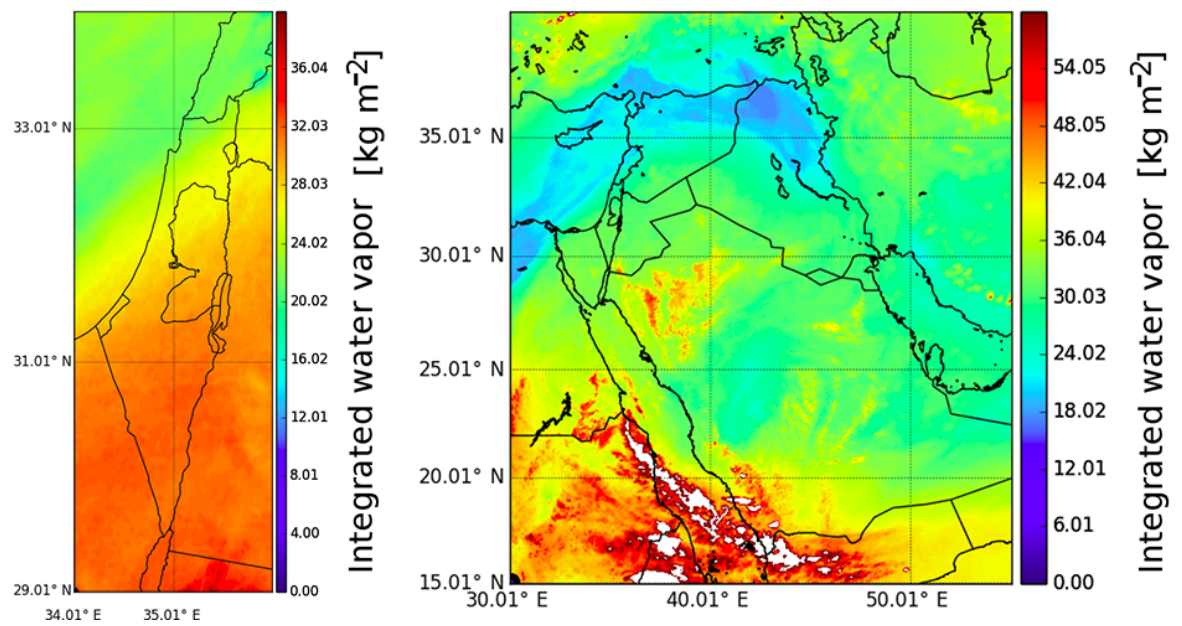

Figure 13. Example for regional WV Distribution maps above Israel (left) and for the entire Middle East region (right) constructed from Meteosat-10 7.3 $\mu \mathrm{m}$ channel for 21 August 2015 at 12:00. Necessary surface temperatures were obtained from (a) IMS stations or (b) Meteosat-10 10.8 $\mu \mathrm{m}$ IR channel. Mean and RMS differences between (a) and (b) are 0.07 and $1.36 \mathrm{~kg} \mathrm{~m}^{-2}$, respectively.

tion at clear sky conditions but with a line of sight (from the satellite to the station) that intersects the clouds (Fig. 11a). In this case, the temperatures obtained from the Meteosat10 images are more than $5 \mathrm{~K}$ cooler relative to the IMS ground measurements and can be removed (Cresswell et al., 1999). Region B represents estimated GPS IWV values taken from stations in cloudy conditions but with a line of sight that does not intersect the clouds (Fig. 11b). In this situation the estimated Meteosat-10 temperatures are approximately equal to the IMS temperatures, but the estimated IWVs are lower than the actual values and can also be removed. Based on Fig. 10 we suggest removing every point under the line count $=2 \cdot$ IWV (the green line indicated in Fig. 10). The result of this procedure leaves us only with region C (Fig. 12).
Using the least squares method (or any linear fitted polynomial function) we can obtain the relation between GPS IWV and the normalized Meteosat-10 pixel values:

$\mathrm{IWV}=0.640 \times$ pix +17.522

where IWV is the GPS IWV and pix is the satellite normalized image pixel value.

\section{Results}

Using the dependency in Eq. (8) we can translate the entire image pixel values into absolute WV values to obtain regional-scale distribution of IWV (Fig. 13). Thus, based on 


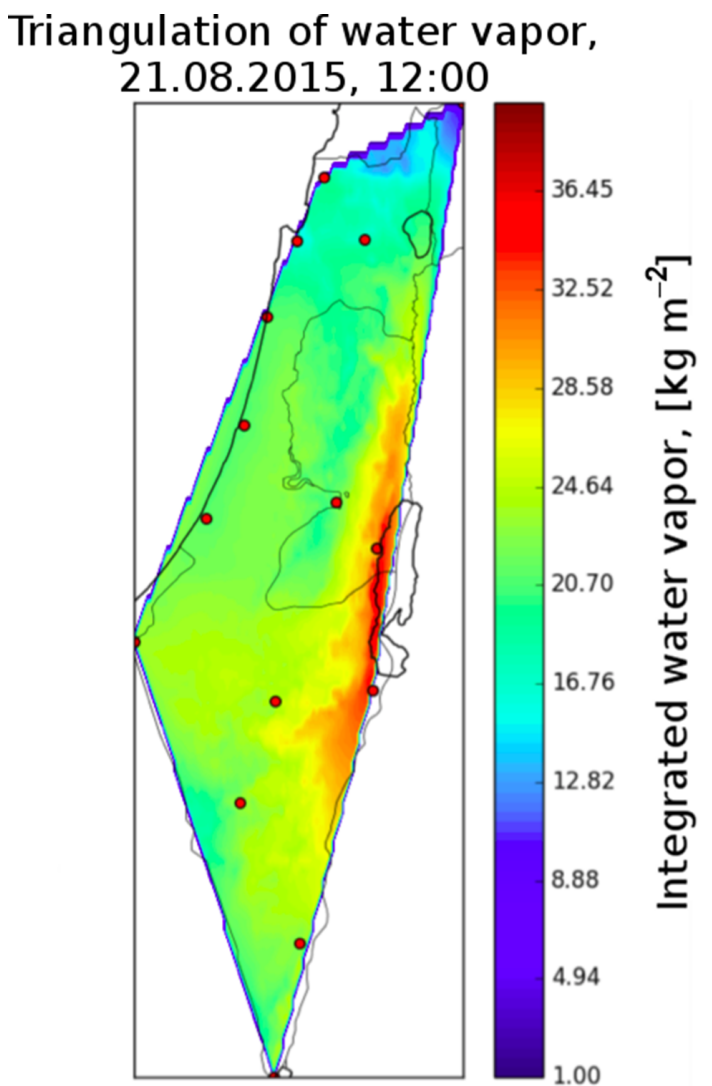

Figure 14. Triangulation of IWV above Israel for 21 August 2015. Red dots represent all available GPS stations (16 in number) that were accounted for.

the dependency of Meteosat-10 image pixel values on GPS IWV absolute values, we are able to construct regional maps of WV distribution using only Meteosat-10 images. An example for a regional WV distribution map of the surrounding Israel and Middle East region, which was produced using the data from Meteosat-10 $7.3 \mu \mathrm{m}$ channel, is shown in Fig. 13. The constructed regional maps, with (a) IMS surface temperatures or (b) Meteosat-10 10.8 $\mu \mathrm{m}$ IR extracted surface temperatures, are in a good agreement (mean and RMS differences between (a) and (b) are 0.07 and $1.36 \mathrm{~mm}$, respectively).

Although we have shown that it is possible to use the mathematical dependency between the normalized Meteosat-10 $7.3 \mu \mathrm{m}$ channel and GPS IWV (both with IMS surface temperatures or Meteosat-10 $10.8 \mu \mathrm{m}$ IR extracted surface temperatures), the best approach for constructing regional $\mathrm{WV}$ maps would be interpolating sufficient GPS IWV data in the desired region. For Israel, there are currently only 24 permanent GPS stations that are fully operational, but data are not always available. For example, the largest number of GPS station that we could retrieve using the SOPAC archive during 2015 was 16 . However, when all available GPS data are interpolated using Delaunay triangulation (bilinear inter-

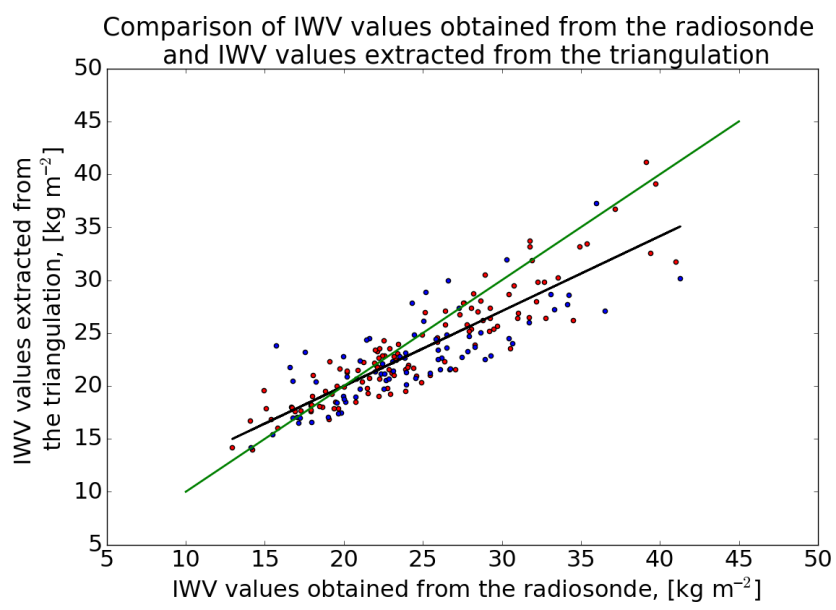

Figure 15. Comparison between triangulation procedure and absolute IWV value obtained from radiosondes measurements. Red dots represent values of 12:00 pm, and blue dots represent values of 00:00 am. RMS values for the entire data set, daytime and nighttime sets are $3.14,2.67$ and $3.74 \mathrm{~kg} \mathrm{~m}^{-2}$, respectively. Mean values for the entire data set, daytime and nighttime sets are 1.31, 1.11 and $1.59 \mathrm{~kg} \mathrm{~m}^{-2}$, respectively. Correlation coefficients $R^{2}$ are 0.76 for the entire data set (indicated by the black line), 0.84 for daytime and 0.61 for nighttime set. The green line represents the area where both data sets are completely equal.

polation) for each specified date and time, an accurate (vs. radiosondes observations) regional $\mathrm{WV}$ maps can be constructed. Since the interpolation is implemented in a region of highly varying terrain, it is important to take the topography into account instead of interpolating across terrain features (Reuveni et al., 2015).

Consequently, WV estimates at points above sea level height $(h)$ are scaled to sea level (sl), using a scale height $(S)$ for the wet delays:

$N_{\mathrm{sl}}=N_{h} e^{-\frac{h}{S}}$.

The scale heights used for the wet delay is $3000 \mathrm{~m}$ (Means, 2011; Means and Cayan, 2013). After applying the interpolation to sea level, the interpolated WV field is then separately scaled to terrain elevation using the identical scale heights and a 6 arcsec digital elevation model. Figure 14 represents the regional WV map produced from the above specified triangulation procedure for 21 August 2015 at 12:00.

As mentioned above, the best way to determine the accuracy of regional WV map (constructed from triangulating all available GPS data) is to compare the WV values above the exact location of the radiosonde observations are taken (i.e., at Bet Dagan site). On this basis, we produced 240 consecutive WV maps for 2015 and compared the values at each map above Bet Dagan to radiosonde WV observations (Fig. 15). RMS values for the entire data set, daytime and nighttime are $3.14,2.67$ and $3.74 \mathrm{~kg} \mathrm{~m}^{-2}$, respectively. Mean values for the entire data set, daytime and nighttime sets are 1.31, 1.11 and 


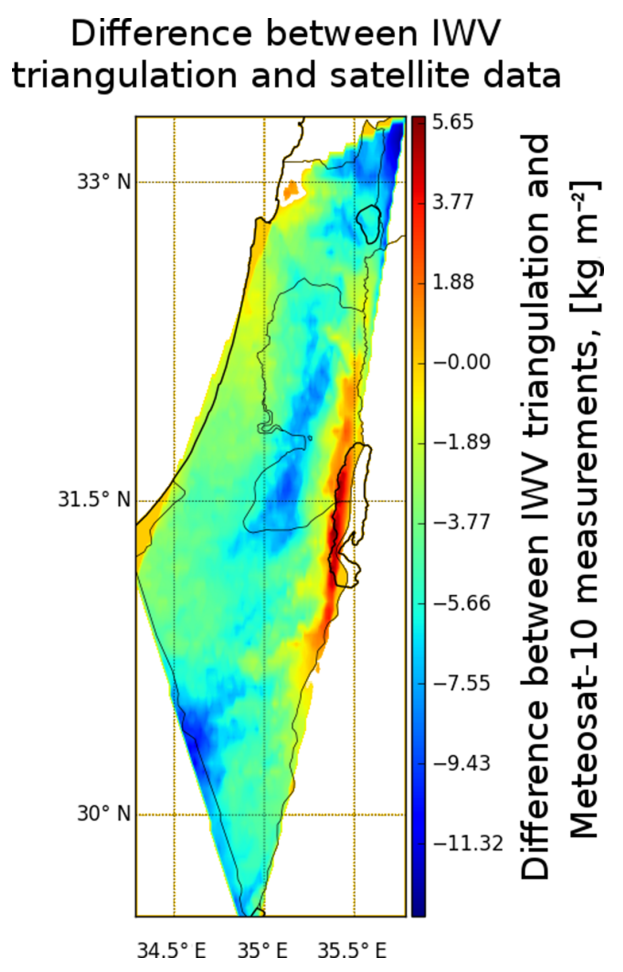

Figure 16. Comparison between triangulated GPS-IWV and WV distribution maps constructed from Meteosat-10 7.3 $\mu \mathrm{m}$ channel for 21 August 2015 at 12:00. Comparison between the two shows a good agreement with mean and RMS differences of 2.75 and $4.55 \mathrm{~kg} \mathrm{~m}^{-2}$, respectively. Meteosat-10 pixel resolution fails to capture small changes in the topography and presents averaged WV estimations above the Golan Heights and Dead Sea.

$1.59 \mathrm{~kg} \mathrm{~m}^{-2}$, respectively. Correlation coefficients $\left(R^{2}\right)$ for the entire data set, daytime and nighttime sets are $0.76,0.84$ and 0.61 respectively.

Furthermore, the constructed GPS WV regional maps using the triangulation procedure can be used as a reference grid (for areas inside the maps that are overlapped since the triangulation can be applied only within the GPS network) for assessing the constructed regional maps of WV distribution extracted from the normalized Meteosat-10 $7.3 \mu \mathrm{m}$ channel. A comparison between the two techniques for 21 August 2015 at 12:00 shows good agreement with mean and RMS differences of 2.75 and $4.55 \mathrm{~mm}$, respectively (Fig. 16). The relatively large differences appear near the mountains (the Golan Heights and Dead Sea), where the Meteosat-10 pixel resolution fails to capture small changes in the topography and presents averaged WV estimations.

\section{Conclusions}

In this work we have presented two different approaches for deriving regional WV distribution maps: triangulating WV estimations based on GPS ZWD and surface temperatures extracted from Meteosat-10 10.8 $\mu \mathrm{m}$ IR channel or, alternatively, converting Meteosat-10 7.3 $\mu \mathrm{m}$ WV pixel values using a mathematical dependency to a known estimated GPS WV value.

The main advantage of using the converted Meteosat-10 $7.3 \mu \mathrm{m} \mathrm{WV}$ pixel values is that we can potentially produce WV distribution maps using the Meteosat-10 data and a small number of GPS station data. The main disadvantage of this technique is the uncertainty regarding the extremely high (and low) satellite pixel values. Low pixel value means that amount of water in the surrounding area is very high, and most likely this is due to cloud. Due to the fact that the emitted satellite radiation cannot penetrate beneath cloud, the amount of WV might not be fitted while constructing the dependency. Therefore, it is useful to combine different channels, e.g., VIS and WV or IR and WV, since the cloud temperature is much lower than the ground temperature. The most common way to measure absolute WV is using radiosondes; however, since it allows estimating WV values only above one corresponding radiosonde point, here it is mostly used for validating the accuracy of the other technics.

The best way to construct regional WV maps is by interpolating WV estimations based on GPS ZWD values, since it allows obtaining the most accurate WV values distributed over relatively large areas. The results obtained from interpolation are in good agreement with the radiosonde data mainly during daytime $\left(R^{2}=0.84\right)$, but they indicate some differences during nighttime $\left(R^{2}=0.61\right)$ and can account for the day-night differences in radiosonde relative humidity measurements (Li et al., 2003). The constructed GPS WV regional maps can also be used as a reference grid for assessing the regional maps of WV distribution extracted from the normalized Meteosat-10 7.3 $\mu \mathrm{m}$ channel. A comparison between the two techniques show that the constructed Meteosat-10 WV maps fails to take into account small changes in topography (i.e., mountains which are consist of both highland and lowland). For example, differences at the Golan Heights and Dead Sea are extremely large due to the relatively low resolution of Meteosat-10 $\left(5 \times 5 \mathrm{~km}^{2}\right.$ pixel $\left.^{-1}\right)$, which causes the images to represent averaged values of $\mathrm{WV}$ from the $5 \times 5 \mathrm{~km}^{2}$ square.

Furthermore, we can also conclude that the temperature obtained from the Meteosat-10 $10.8 \mu \mathrm{m}$ IR channel can be used for GPS WV precise calculations while using it along with the ZWD estimations. However, special care is required when using the satellite-inferred surface temperature due to the existence of clouds and surrounding areas of water. A comparison of VIS and IR bands might help to exclude clouds and reduce inaccuracies while extracting surface temperatures. The presented strategy can provide high temporal and spatial IWV distribution, which is required as part of the accurate and comprehensive initial conditions provided by upper-air observation systems at temporal and spatial resolutions consistent with the models assimilating them. 
Competing interests. The authors declare that they have no conflict of interest.

Acknowledgements. Continuous GPS data were provided by SCIGN, operated by the Scripps Orbit and Permanent Array Center (SOPAC). This work was founded by the Israeli Ministry of Science, Technology \& Space grant 3-11687.

Edited by: J. Jones

Reviewed by: three anonymous referees

\section{References}

Bar-Sever, Y. E., Kroger, P. M., and Borjesson, J. A.: Estimating horizontal gradients of tropospheric path delay with a single GPS receiver, J. Geophys. Res., 103, 5019, doi:10.1029/97JB03534, 1998.

Bertiger, W., Desai, S. D., Haines, B., Harvey, N., Moore, A. W., Owen, S., and Weiss, J. P.: Single receiver phase ambiguity resolution with GPS data, J. Geodesy, 84, 327-337, doi:10.1007/s00190-010-0371-9, 2010.

Bevis, M., Businger, S., Herring, T. A., Rocken, C., Anthes, R. A., and Ware, R. H.: GPS meteorology: Remote sensing of atmospheric water vapor using the global positioning system, J. Geophys. Res., 97, 15787, doi:10.1029/92JD01517, 1992.

Bevis, M., Businger, S., Chiswell, S., Herring, T. A., Anthes, R. A., Rocken, C., and Ware, R. H.: GPS Meteorology: Mapping Zenith Wet Delays onto Precipitable Water, J. Appl. Meteorol., 33, 379-386, doi:10.1175/1520-0450(1994)033<0379:GMMZWD> 2.0.CO;2, 1994.

Bock, O., Bosser, P., Pacione, R., and Nuret, M.: A high-quality reprocessed ground-based GPS dataset for atmospheric process studies, radiosonde and model evaluation, and reanalysis of HyMeX Special, Q. J. Roy. Meteorol. Soc., 142, 56-71, doi:10.1002/qj.2701, 2015.

Boehm, J., Werl, B., and Schuh, H.: Troposphere mapping functions for GPS and very long baseline interferometry from European Centre for Medium-Range Weather Forecasts operational analysis data, J. Geophys. Res.-Sol. Ea., 111, B02406, doi:10.1029/2005JB003629, 2006.

Bréon, F.-M., Jackson, D. L., and Bates, J. J.: Calibration of the Meteosat water vapor channel using collocated NOAA/HIRS 12 measurements, J. Geophys. Res.-Atmos., 105, 11925-11933, doi:10.1029/2000JD900031, 2000.

Calori, A., Santos, J., Blanco, M., and Pessano, H.: Ground-based GNSS network and integrated water vapor mapping during the development of severe storms at the Cuyo region (Argentina), Atmos. Res., 176-177, 267-275, 2016.

Cresswell, M., Morse, A., and Thomson, M.: Estimating surface air temperatures, from Meteosat land surface temperatures, using an empirical solar zenith angle model, Int. J., 20, 1125-1132, doi:10.1080/014311699212885, 1999.

Dai, A., Wang, J., Thorne, P. W., Parker, D. E., Haimberger, L., Wang, X. L., Dai, A., Wang, J., Thorne, P. W., Parker, D. E., Haimberger, L., and Wang, X. L.: A New Approach to Homogenize Daily Radiosonde Humidity Data, J. Climate, 24, 965-991, doi:10.1175/2010JCLI3816.1, 2011.
Dai, A., Li, H., Sun, Y., Hong, L., and Chou, C.: The relative roles of upper and lower tropospheric thermal contrasts and tropical influences in driving Asian summer monsoons, J. Geophys. Res.Atmos., 18, 7024-7045, doi:10.1002/jgrd.50565, 2013.

Dayan, U. and Rodnizki, J.: The Temporal Behavior of the Atmospheric Boundary Layer in Israel, J. Appl. Meteorol., 38, 830-836, doi:10.1175/1520-0450(1999)038< 0830:ТTBOTA> 2.0.CO;2, 1999.

Dembelov, M., Bashkuev, Y., and Lukhnev, A.: Diagnostics of atmospheric water vapor content according to GPS measurements, Atmos. Ocean. Opt., 28, 291-296, 2015.

Duan, J., Bevis, M., Fang, P., Bock, Y., Chiswell, S., Businger, S., Rocken, C., Solheim, F., van Hove, T., Ware, R., McClusky, S., Herring, T. A., and King, R. W.: GPS Meteorology: Direct Estimation of the Absolute Value of Precipitable Water, J. Appl. Meteorol., 35, 830-838, doi:10.1175/15200450(1996)035<0830:GMDEOT> 2.0.CO;2, 1996.

Elliott, W. and Gaffen, D.: On the utility of radiosonde humidity archives for climate studies, B. Am. Meteorol. Soc., 72, 15071520, 1991.

Flato, G., Marotzke, J., Abiodun, B., and Braconnot, P.: Evaluation of Climate Models, in: Climate Change 2013: The Physical Science Basis, Contribution of Working Group I to the Fifth Assessment Report of the, Clim. Chang, available at: http://elib.dlr. de/95697/ (last access: 3 November 2016), 2013.

Free, M. and Durre, I.: Creating climate reference datasets, B. Am. Meteorol. Soc., 83, 891-899, 2002.

Guerova, G., Jones, J., Dousa, J., Dick, G., Haan, S. de, Pottiaux, E., Bock, O., Pacione, R., Elgered, G., and Vedel, H.: Advanced Global Navigation Satellite Systems Tropospheric Products for Monitoring Severe Weather Events and Climate (GNSS4SWEC), 2013.

de Haan, S., Barlag, S., Baltink, H. K., Debie, F., van der Marel, H., Haan, S. de, Barlag, S., Baltink, H. K., Debie, F., and van der Marel, H.: Synergetic Use of GPS Water Vapor and Meteosat Images for Synoptic Weather Forecasting, J. Appl. Meteorol., 43, 514-518, doi:10.1175/1520-0450(2004)043< 0514:SUOGWV> 2.0.CO;2, 2004.

Hagemann, S. and Bengtsson, L.: On the determination of atmospheric water vapor from GPS measurements, J. Geophys., 108, 4678, doi:10.1029/2002JD003235, 2003.

Hanssen, R., Feijt, A., and Klees, R.: Comparison of Precipitable Water Vapor Observations by Spaceborne Radar Interferometry and Meteosat $6.7 \mu \mathrm{m}$ Radiometry, J. Atmos. Ocean. Tech., 18, 756-764, 2001.

Heise, S., Dick, G., Gendt, G., and Schmidt, T.: Integrated water vapor from IGS ground-based GPS observations: initial results from a global 5-min data set, available at: http://gfzpublic.gfz-potsdam.de/pubman/item/escidoc: 239433:1/component/escidoc:239432/13798.pdf (last access: 6 October 2016), 2009.

Hordyniec, P., Bosy, J., and Rohm, W.: Assessment of errors in Precipitable Water data derived from Global Navigation Satellite System observations, J. Atmos. Sol.-Terr. Phy., doi:10.1016/j.jastp.2015.04.012, in press, 2015.

Ivančan-Picek, B., Horvath, K., Mahović, N. S., and Gajić-Čapka, M.: Forcing mechanisms of a heavy precipitation event in the southeastern Adriatic area, Nat. Hazards, 72, 1231-1252, doi:10.1007/s11069-014-1066-y, 2014. 
Jiang, J. H., Su, H., Zhai, C., Perun, V. S., Del Genio, A., Nazarenko, L. S., Donner, L. J., Horowitz, L., Seman, C., Cole, J., Gettelman, A., Ringer, M. A., Rotstayn, L., Jeffrey, S., Wu, T., Brient, F., Dufresne, J.-L., Kawai, H., Koshiro, T., Watanabe, M., LÉcuyer, T. S., Volodin, E. M., Iversen, T., Drange, H., Mesquita, M. D. S., Read, W. G., Waters, J. W., Tian, B., Teixeira, J., and Stephens, G. L.: Evaluation of cloud and water vapor simulations in CMIP5 climate models using NASA "A-Train" satellite observations, J. Geophys. Res.-Atmos., 117, D14105, doi:10.1029/2011JD017237, 2012.

Kley, D., Stone, E. and Henderson, W.: SPARC assessment of upper tropospheric and stratospheric water vapor, WCRP 113, WMO/TD-1043, SPARC Rep. 2, World Clim. Res. Program, Geneva, 312 pp., 2000.

Li, Z., Muller, J. P., and Cross, P.: Comparison of precipitable water vapor derived from radiosonde, GPS, and Moderate-Resolution Imaging Spectroradiometer measurements, J. Geophys. Res.Atmos., 108, 4651, doi:10.1029/2003JD003372, 2003.

Means, J.: GPS precipitable water measurements used in the analysis of California and Nevada climate, available at: http: //adsabs.harvard.edu/abs/2011PhDT.......133M (last access: 15 June 2016), 2011.

Means, J. and Cayan, D.: Precipitable water from GPS Zenith delays using North American regional reanalysis meteorology, Atmos. Ocean. Technol., 30, 485-495, 2013.

Miloshevich, L. M., Vömel, H., Whiteman, D. N., Lesht, B. M., Schmidlin, F. J., and Russo, F.: Absolute accuracy of water vapor measurements from six operational radiosonde types launched during AWEX-G and implications for AIRS validation, J. Geophys. Res., 111, D09S10, doi:10.1029/2005JD006083, 2006.

Moore, A., Small, I., and Gutman, S.: National weather service forecasters use GPS precipitable water vapor for enhanced situational awareness during the southern California summer monsoon, B. Am. Meteorol. Soc., 96, 1867-1877, doi:10.1175/BAMS-D-1400095.1, 2015.

Muller, J.: MSG/ICD/105, available at: http://www.eumetsat.int/ groups/ops/documents/document/pdf_ten_05105_msg_img_ data.pdf (last access: February 2017), 2010.

Reuveni, Y., Kedar, S., Owen, S. E., Moore, A. W., and Webb, F. H.: Improving sub-daily strain estimates using GPS measurements, Geophys. Res. Lett., 39, L11311, doi:10.1029/2012GL051927, 2012.

Reuveni, Y., Kedar, S., Moore, A., and Webb, F.: Analyzing slip events along the Cascadia margin using an improved subdaily GPS analysis strategy, Geophys. J. Int., 198, 1269-1278, doi:10.1093/gji/ggu208, 2014.

Reuveni, Y., Bock, Y., Tong, X., and Moore, A. W.: Calibrating interferometric synthetic aperture radar (InSAR) images with regional GPS network atmosphere models, Geophys. J. Int., 202, 2106-2119, doi:10.1093/gji/ggv253, 2015.

Roca, R., Picon, L., and Desbois, M.: Direct comparison of Meteosat water vapor channel data and general circulation model results, Geophys. Res., 24, 147-150, 1997.

Sadeghi, E. and Mashhadi-Hossainali, M.: Determining precipitable water in the atmosphere of Iran based on GPS zenith tropospheric delays, Ann. Geophys., doi:10.4401/ag-6407, 2014.
Schmetz, J., Tjemkes, S. A., Gube, M., and van de Berg, L.: Monitoring deep convection and convective overshooting with METEOSAT, Adv. Space Res., 19, 433-441, doi:10.1016/S02731177(97)00051-3, 1997.

Schroedter-Homscheidt, M., Drews, A., and Heise, S.: Total water vapor column retrieval from MSG-SEVIRI split window measurements exploiting the daily cycle of land surface temperatures, Remote Sens. Environ., 112, 249-258, doi:10.1016/j.rse.2007.05.006, 2008.

Shangguan, M., Heise, S., Bender, M., and Dick, G.: Validation of GPS atmospheric water vapor with WVR data in satellite tracking mode, available at: http://eprints.uni-kiel.de/26354/ (last access: 6 January 2017), 2015.

Soden, B. and Lanzante, J.: An assessment of satellite and radiosonde climatologies of upper-tropospheric water vapor, J. Climate, 9, 1235-1250, 1997.

Soden, B. J., Turner, D. D., Lesht, B. M., and Miloshevich, L. M.: An analysis of satellite, radiosonde, and lidar observations of upper tropospheric water vapor from the Atmospheric Radiation Measurement Program, J. Geophys. Res.-Atmos., 109, D04105, doi:10.1029/2003JD003828, 2004.

Solomon, S., Rosenlof, K. H., Portmann, R. W., Daniel, J. S., Davis, S. M., Sanford, T. J., and Plattner, G.-K.: Contributions of stratospheric water vapor to decadal changes in the rate of global warming, Science, 327, 1219-23, doi:10.1126/science.1182488, 2010.

Vedel, H., Huang, X., Haase, J., and Ge, M.: Impact of GPS zenith tropospheric delay data on precipitation forecasts in Mediterranean France and Spain, Geophys. Res., 31, L02102, doi:10.1029/2003GL017715, 2004.

Velden, C. S., Hayden, C. M., Nieman, S. J., Menzel, W. P., Wanzong, S., and Goerss, J. S.: Upper-Tropospheric Winds Derived from Geostationary Satellite Water Vapor Observations, available at: http://ntrs.nasa.gov/search.jsp?R=19980018993 (last access: 25 May 2016), 1997.

van Vleck, J. H.: The Absorption of Microwaves by Uncondensed Water Vapor, Phys. Rev., 71, 425-433, doi:10.1103/PhysRev.71.425, 1947.

Wang, J., Dai, A., Mears, C., Wang, J., Dai, A., and Mears, C.: Global Water Vapor Trend from 1988 to 2011 and Its Diurnal Asymmetry Based on GPS, Radiosonde, and Microwave Satellite Measurements, J. Climate, 29, 5205-5222, doi:10.1175/JCLI-D15-0485.1, 2016.

Ware, R. and Alber, C.: Sensing integrated water vapor along GPS ray paths, Geophys. Res., 24, 417-420, 1997.

Wdowinski, S. and Eriksson, S.: Geodesy in the 21st Century, Eos, 90, 153-155, 2009.

Zumberge, J. F., Heflin, M. B., Jefferson, D. C., Watkins, M. M., and Webb, F. H.: Precise point positioning for the efficient and robust analysis of GPS data from large networks, J. Geophys. Res., 102, 5005-5017, doi:10.1029/96JB03860, 1997. 